\title{
Generation of a phagemid mouse recombinant antibody fragment library by multisite-directed mutagenesis
}

\author{
Laura-Lee Clancy Kelley and Cory Momany \\ University of Georgia, Athens, GA, USA \\ BioTechniques 35:750-758 (October 2003)
}

\begin{abstract}
A nonimmune phagemid recombinant antibody fragment ( $r F a b)$ library was generated with a nominal diversity of $1.16 \times 10^{7}$ using the QuikChange ${ }^{\circledR}$ Multi Site-Directed Mutagenesis kit. Two degenerate primers spanning the third complementarity-determining region $(C D R)$ loops of the antibody fragment light and heavy chain were mutated such that eight or nine amino acids were randomly changed per CDR loop. Seven proteins were used to evaluate the library quality. Protein-specific rFab antibodies were selected after three panning cycles. From $12 \%$ to $64 \%$ of the randomly selected colonies produced positive ELISA signals to the phagemid rFabs. Multisite-directed mutagenesis allowed a diverse rFab library to be rapidly constructed while retaining the structural framework of a Fab that had been optimized for production in Escherichia coli.
\end{abstract}

\section{INTRODUCTION}

Phagemid and phage libraries of various types of antibody fragments are being exploited for commercial, medi$\mathrm{cal}$, and fundamental research purposes (1-14). The successful completion of many genomes has spawned "proteome projects," where high-throughput methodologies are applied to gain insight into protein structure and function. As an alternative to conventional crystallization techniques used for determining the 3-D structure of proteins, we are developing recombinant antibody fragments (rFabs) as co-crystallization reagents $(15,16)$ that can be used for structural genomics. An important aspect of our use of $\mathrm{rFabs}$ is that a combinatorial library must be constructed so that a selection system, in this case phage display technology (17), can be used to select for rFabs recognizing diverse targets. The construction of phage-antibody libraries generally employs fairly laborious approaches that can include multiple cloning steps, cDNA amplification, and recombination. Diversities (effective library size) range from $10^{6}$ to $10^{10}(13)$. Many of these antibody libraries are initially derived from immune cells $(2,18)$. However, synthetic libraries have been generated (19), which form the basis for our library's approach.
Fabs contain six complementaritydetermining region (CDR) loops, three in the heavy chain and three in the light chain, which recognize diverse antigens. We utilized the QuikChange ${ }^{\circledR}$ Multi Site-Directed Mutagenesis kit (Stratagene, La Jolla, CA, USA) $(20,21)$ to randomly mutate the third CDR loops of both the heavy and light chain of an rFab optimized for efficient prokaryotic expression. By using multisite mutagenesis, a complex library was constructed in minimal time without multiple subcloning steps.

\section{MATERIALS AND METHODS}

\section{Chemical and Biological Reagents}

The Escherichia coli XL1-blue strain and PfuTurbo ${ }^{\circledR}$ DNA polymerase were purchased from Stratagene (20). A QIAquick ${ }^{\circledR}$ PCR purification kit was purchased from Qiagen (Valencia, CA, USA). T4 DNA ligase and carbenicillin were purchased from Invitrogen (Carlsbad, CA, USA). Rabbit anti-mouse immunoglobulin $\mathrm{G}$ ( $\operatorname{IgG})\left[\mathrm{F}\left(\mathrm{ab}^{\prime}\right) 2\right]$-alkaline phosphatase (RAM-AP) came from Pierce Biotechnology (Rockford, IL, USA), and phosphatase substrate tablets came from Sigma (St. Louis, MO, USA). Isopropyl- $\beta$-D-thiogalactopyranoside (IPTG), 3-(N-morpholino) propane-sulfonic acid (MOPS) buffer, yeast extract, tryptone, tetracycline, and kanamycin were purchased from Fisher Scientific (Pittsburgh, PA, USA). SacI, $S p e \mathrm{I}, \mathrm{XbaI}$, and $\mathrm{XhoI}$ restriction enzymes were purchased from New England BioLabs (Beverly, MA, USA). Super Broth (SB) consisted of $30 \mathrm{~g}$ of tryptone plus $20 \mathrm{~g}$ yeast extract and $10 \mathrm{~g}$ of MOPS per liter titrated to $\mathrm{pH}$ 7.0. High-strength analytical-grade agarose was purchased from Bio-Rad Laboratories (Hercules, CA, USA). Degenerate light chain (a 65-base oligomer, LCCDR3RAN8) and heavy chain primers (a 68-base oligomer, HCCDR3RAN9) were synthesized, 5' phosphorylated and polyacrylamide gel electrophoresis (PAGE)-purified by Sigma-Genosys (Cambridgeshire, UK). The primer sequences were LCCDR3RAN8: 5'-CTGCAATGTATTTCTGTCAG(NNK) ${ }_{8}$ TTCGGTGCTGGGACCAAGGTG-3'; andHCCDR3RAN9:5'-GTCTATTACTGTGCAAGATGG(NNK) TACTGGGGCCAAGGCACCAC-3', where $\mathrm{N}$ is $\mathrm{A}, \mathrm{T}, \mathrm{C}$, or $\mathrm{G}$, and $\mathrm{K}$ is $\mathrm{G}$ or $\mathrm{T}$. The design and construction of the pComb3H-Fab4 plasmid $\left(\right.$ GenBank $^{\circledR}$ acquisition number AY254174), the template vector for the library construction, will be described elsewhere. Briefly, it consisted of light and heavy chains (Fab portion) of Mab25.3, a monoclonal antibody that recognizes the human immunodeficiency virus (HIV)-1 capsid protein (22) cloned into the plasmid pComb3H obtained from Dr. Carlos Barbas III (Scripps Research Institute, La Jolla, CA, USA) (23). Several modifications were made to the light and heavy chains to improve the stability and purification behavior of the Fab for optimal expression in E. coli. Electrocompetent XL-1 Blue cells prepared in house had a transformation efficiency of $4 \times 10^{10}$ transformants/ $\mu \mathrm{g}$ using pUC19 as control (23).

\section{Library Construction and Testing}

Plasmid pComb3H-Fab4 was used as a template for multisite mutagenesis following the manufacturer's instructions with some modifications. Table 1 shows the parameters for the PCR and the transformation results. The pUC controls included with the kit were performed separately, because pUC optimal PCR conditions were different from the 
Table 1. PCR Parameters Used to Optimize the Construction of an rFab Library

\begin{tabular}{|c|c|c|c|}
\hline Component & $\begin{array}{l}\text { Control } \\
\text { Reaction } \\
(\mu \mathrm{L})\end{array}$ & $\begin{array}{l}\text { MultiMix } \\
\text { Enzyme } \\
\text { Blend } \\
\quad(\mu \mathrm{L})\end{array}$ & $\begin{array}{c}\text { MultiMix Enzyme } \\
\text { Blend Plus } \\
\text { PfuTurbo } \\
\text { DNA Polymerase } \\
(\mu \mathrm{L})\end{array}$ \\
\hline $\begin{array}{l}10 \times \text { QuikChange Multi reaction } \\
\text { buffer }\end{array}$ & 2.5 & 5.0 & 5.0 \\
\hline Sterile, Nanopure ${ }^{\circledR}$ water & 19.5 & 35.0 & 35.0 \\
\hline $\begin{array}{l}\text { Double-stranded DNA template } \\
\text { pComb3H-Fab4 }\end{array}$ & 1.0 & 2.0 & 2.0 \\
\hline \multicolumn{4}{|l|}{ Mutagenic primers: } \\
\hline LCCDR3RAN8 (144 ng/ $\mu \mathrm{L})$ & 0 & 2.0 & 2.0 \\
\hline 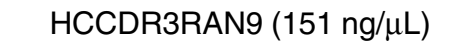 & 0 & 2.0 & 2.0 \\
\hline dNTP mixture & 1.0 & 2.0 & 2.0 \\
\hline PfuTurbo DNA polymerase & 0 & 0 & 1.0 \\
\hline $\begin{array}{l}\text { QuikChange Multi enzyme } \\
\text { blend }\end{array}$ & 1.0 & 2.0 & 1.0 \\
\hline Total Reaction Volume & 25.0 & 50.0 & 50.0 \\
\hline \multicolumn{4}{|c|}{$\begin{array}{l}\text { Transformation Results } \\
\qquad(\text { cfus } / \mu \mathrm{L})^{\mathrm{a}}\end{array}$} \\
\hline $\begin{array}{l}\text { Plasmid pComb3H-Fab4 } \\
\text { template }\end{array}$ & $6.2 \times 10^{3 b, c}$ & $2.8 \times 10^{5 d}$ & $1.5 \times 10^{6}$ \\
\hline $\begin{array}{l}\text { Triple mutant control using } \\
\text { pWS-3 and primers from kit }\end{array}$ & & & $\begin{array}{l}7.2 \times 10^{4} \text { blue/ } \\
1.7 \times 10^{5} \text { total }^{\mathrm{b}, \mathrm{c}}\end{array}$ \\
\hline \multicolumn{4}{|c|}{ rFAB, recombinant antibody fragment. } \\
\hline \multicolumn{4}{|c|}{$\begin{array}{l}\text { Three dilutions of cells were prepared with the numbers reported from the } \\
\text { plates with }<200 \text { colonies. Library size is calculated as mean colony-forming } \\
\text { units (cfus) } / \mu \mathrm{L} \text { plating volume } \times 550 \mu \mathrm{L} \text { transformation volume } \times \text { total reaction } \\
\text { volume }(25 \text { or } 50 \mu \mathrm{L}) / 1.5 \mu \mathrm{L} \text { transformed DNA as per Hogrefe et al. }(21) \text {. For a } \\
\text { direct comparison to Reference } 21 \text {, the library sizes should be divided by } 2 \text { for } \\
\text { the } 50-\mu \mathrm{L} \text { reactions. Transformations were performed in duplicate using the su- } \\
\text { percompetent cells provided in the kit. }\end{array}$} \\
\hline \multicolumn{4}{|c|}{ bOnly one transformation performed. } \\
\hline \multicolumn{4}{|l|}{ c25 $\mu \mathrm{L}$ reaction volume. } \\
\hline${ }^{\mathrm{d}}$ Average of two transformations & & & \\
\hline
\end{tabular}

library. For the final library, a total of 10 reactions $(50 \mu \mathrm{L}$ reaction volume each) were performed. Optimized cycling parameters using a RoboCycler ${ }^{\circledR}$ (Stratagene) were: 1 cycle at $95^{\circ} \mathrm{C}, 30$ cycles of $1 \mathrm{~min}$ at $95^{\circ} \mathrm{C}, 1 \mathrm{~min} 30 \mathrm{~s}$ at $63^{\circ} \mathrm{C}$, and a final extension cycle of $8 \mathrm{~min}$ at $65^{\circ} \mathrm{C}$. Five micrograms of the DpnItreated, PCR-purified, single-stranded DNA were transformed by electroporation into $1300 \mu \mathrm{L} \mathrm{E}$. coli XL1-blue (six separate transformations). The panning temperature for $30 \mathrm{~min}$, and induced with $0.5 \mathrm{mM}$ IPTG. The supernatants from cultures grown overnight at room temperature were tested by ELISA for the production of $\mathrm{pComb} 3 \mathrm{H}-\mathrm{Fab}$ specific for the target proteins (results are shown in Table 2) (24). An absorbance ratio of at least 2.5 for Fab incubated with immobilized target to Fab incubated without was scored as a "positive" colony.

\section{RESULTS AND DISCUSSION}

The QuikChange Multi Site-Directed Mutagenesis kit uses one to five primers designed to hybridize to the same strand of DNA in noncontiguous regions. The resulting complementary single-stranded DNA fragments are ligated by a thermophilic ligase in situ (21). While the manufacturer's protocol was largely followed, we found that the yield of DNA could be increased significantly by optimizing the enzyme mixture (Table 1). Since the reaction does not result in binary amplification like a standard PCR, the overall yield of product is low and limits the possible size of the library. As shown in Table 1, matching the volume of QuikChange Multi enzyme blend used with PfuTurbo DNA polymerase consistently produced at least a 3-fold higher number of transformants per reaction volume $\left[5.7 \times 10^{3}\right.$ colonyforming units (cfu) $/ \mu \mathrm{L}$ without added polymerase versus $2.9 \times 10^{4} \mathrm{cfu} / \mu \mathrm{L}$ with added polymerase]. By also allowing the total reaction volume to be doubled (the Multi enzyme blend is limiting in the kit), the final library size could be effectively increased 10-fold. To ensure that the dilution of the enzyme blend with compensating PfuTurbo DNA polymerase did not lower the mutation efficiency, the pWS-3 triple-site mutagenesis control reaction provided with the kit was performed. The transformation efficiency (as $\mathrm{cfu} / \mu \mathrm{L}$ ) for the control triple mutation with the supplemented polymerase was greater than 4-fold better than that reported by Hogrefe et al. (21). The percentage of triple mutants (42\%) was lower than the average for the control without polymerase, $55 \%$ reported by Hogrefe et al. (21); but 


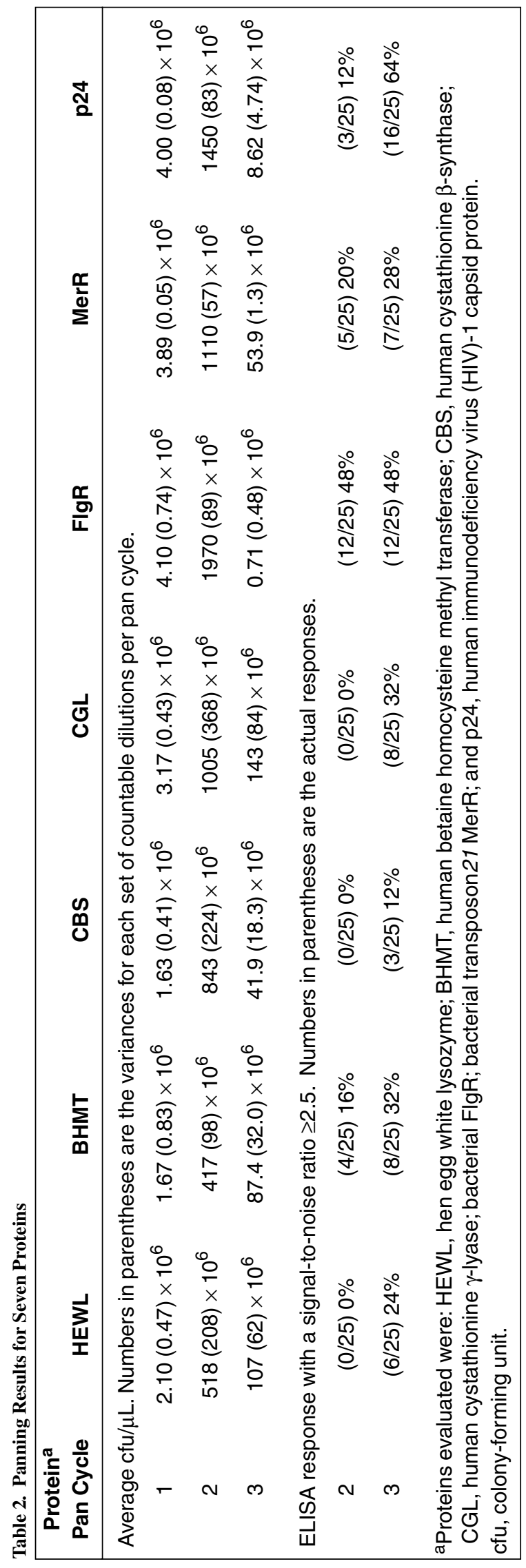

this value would have been $50 \%$ if one low colony count were omitted from the average value. Using the optimized conditions, 10 reactions $(50 \mu \mathrm{L}$ each) were combined and had a nominal diversity of $1.16 \times 10^{7}$ cfus. Varying the ratio of PfuTurbo DNA polymerase to the enzyme blend is thus a useful parameter to examine before creating large-scale libraries using this system.

Another significant deviation from the manufacturer's protocol was that much longer mutation primers (longer in length as well as containing more mutations) than recommended were used. Our primers had approximately 20 to 21 bases on the $5^{\prime}$ and $3^{\prime}$ ends complementary to the DNA flanking the third CDR loops of the heavy and light chains (Figure 1). Twenty-four or twenty-seven bases in the CDR loops were mutated following an NNK scheme, where $\mathrm{K}$ equals $G$ and $T$ are in the third codon position. This scheme thus introduced mutations in eight or nine amino acids of the two CDR loops encoding all 20 amino acids with minimal stop codons. As evidenced by the high transformation efficiency and the production of a functional library with ELISA signals to multiple proteins, the primers were clearly functional.

Table 2 shows that we obtained selection of phagmid-rFabs against seven antigen proteins after three panning cycles. Depending on the target protein (panogen), the number of rFab-phagemids (out of 25 tested) that had positive ELISA signals varied between $12 \%$ and $64 \%$. Since the parent $\mathrm{rFab}$ was derived from murine Mab25.3 specific for HIV-1 capsid protein p24 (22), p24 was included as a control. We expected to see a substantial selection in the panning of phagemids specific to the $\mathrm{p} 24$. Surprisingly, p24 was not significantly better than the other six protein targets in the number of transformants per panning round. The p24 capsid protein did surpass the other protein targets in the percentage of transformants (64\%) that carried the phagemid-rFabs specific for the target, but only ranged from 2- to 5 -fold greater when compared with the other phagemid-rFabs (Table 2). However, the effective total number of phagemid-rFabs (total number of cfus times the percentage of positive ELISA signals) produced against their target at the end of the third panning cycle has four of the six other protein targets outperforming the p24 capsid protein. As a final check of the panning process, two rFab-plasmids were purified and examined by restriction enzyme analysis (Figure 2). The recovered plasmids contained appropriate restriction sites and fragments corresponding to the light and heavy chain Fab DNA sequences (Figure 1).

Our goal was to create high-affinity rFabs for co-crystallization with novel protein targets in which the basic scaffold of the co-crystallization Fab was unchanged. Thus, random mutagenesis approaches, such as error-prone PCR, were not desirable. While the suggested use of the QuikChange Multi Site-Directed Mutagenesis kit was for multiple sites with two to three nucleotide changes per degenerate primer, 24 and 27 nucleotides were simultaneously mutagenized in our experiment. Antibody libraries made with more laborious approaches have been reported with diversities ranging from $10^{6}$ to $10^{10}$ (13). Our library of $1.16 \times$ $10^{7}$ different rFabs was quickly generated and is of a high quality as judged by our ability to obtain ELISA positive clones to a wide variety of proteins. Our results suggest that this mutagenesis kit is quite versatile for preparing large-scale combinatorial libraries. 


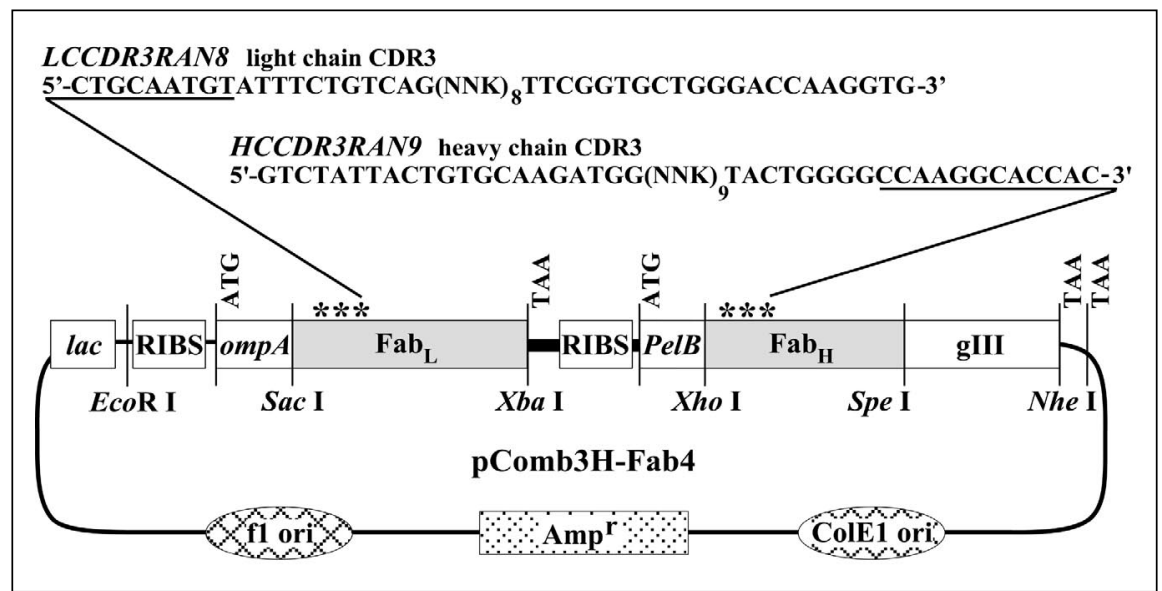

Figure 1. Restriction enzyme sites and genetic features of the pComb3H-Fab4 plasmid used for building the antibody fragment (Fab) library. Stars represent relative locations of the six complementarity-determining region (CDR) loops in the Fab light and heavy chains. The genes are under the control of a lac operator and promoter, and RIBS represents the ribosome binding site. The phage gene III protein (gIII) is in-frame with the Fab heavy chain.

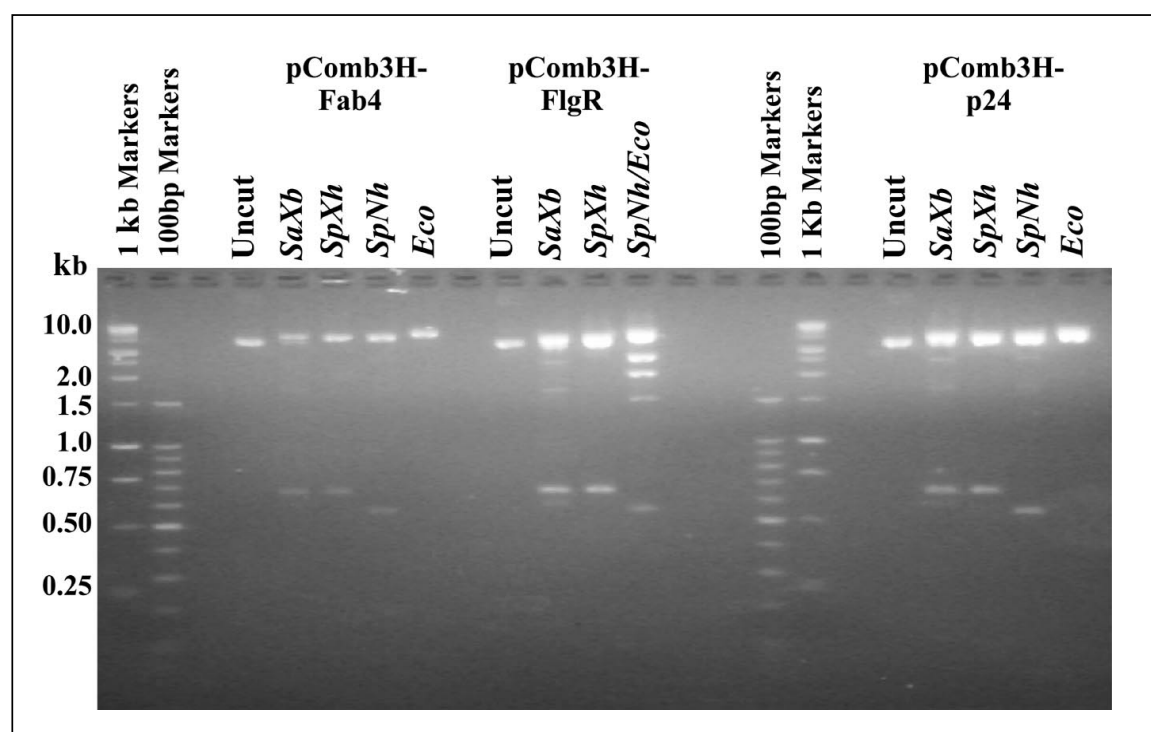

Figure 2. Restriction endonuclease analysis of selected ELISA positive clones from the antibody fragment (Fab) library. Plasmid pComb3H-Fab4 is the starting DNA used for the library construction, pComb3H-FlgR is DNA isolated from a single ELISA positive colony selected from the third pan round against FlgR, and the pComb3H-p24 is similarly selected against the human immunodeficiency virus (HIV) p24. See Figure 1 for the relative location of the specific endonuclease sites. Abbreviations are: $\mathrm{SaXb}, \mathrm{SacI} / \mathrm{XbaI}$; XhSp, XhoI/SpeI; SpNh, SpeI/NheI; and Eco, EcoRI for the respective restriction enzymes used.

\section{ACKNOWLEDGMENTS}

We thank Ladislau Kovari and Michael Rossman for providing us with mouse monoclonal antibody cell line for Mab25.3 (originally obtained from Jan McClure) and Anne Summers and Tim Hoover for the MerR and FlgR proteins. Support for this work was funded by grants from the National
Science Foundation (MCB9723244) and the University of Georgia Research Foundation.

\section{REFERENCES}

1.Barbas, C.F., III, A.S. Kang, R.A. Lerner, and S.J. Benkovic. 1991. Assembly of combinatorial antibody libraries on phage surfaces: the gene III site. Proc. Natl. Acad. Sci.
USA 88:7978-7982.

2.Marks, J.D., H.R. Hoogenboom, T.P. Bonnert, J. McCafferty, A.D. Griffiths, and G. Winter. 1991. By-passing immunization. Human antibodies from V-gene libraries displayed on phage. J. Mol. Biol. 222:581-597.

3.Marks, J.D., H.R. Hoogenboom, A.D. Griffiths, and G. Winter. 1992. Molecular evolution of proteins on filamentous phage. Mimicking the strategy of the immune system. J. Biol. Chem. 267:16007-16010.

4.Hoogenboom, H.R., J.D. Marks, A.D. Griffiths, and G. Winter. 1993. Building antibodies from their genes. Rev. Fr. Transfus. Hemobiol. 36:19-47.

5.Press, O.W., J.F. Eary, F.R. Appelbaum, P.J. Martin, C.C. Badger, W.B. Nelp, S. Glenn, G. Butchko, et al. 1993. Radiolabeledantibody therapy of B-cell lymphoma with autologous bone marrow support. N. Engl. J. Med. 329:1219-1224.

6.Rossenu, S., D. Dewitte, J. Vandekerckhove, and C. Ampe. 1997. A phage display technique for a fast, sensitive, and systematic investigation of protein-protein interactions. J. Protein Chem. 16:499-503.

7.Persic, L., A. Roberts, J. Wilton, A. Cattaneo, A. Bradbury, and H.R. Hoogenboom. 1997. An integrated vector system for the eukaryotic expression of antibodies or their fragments after selection from phage display libraries. Gene 187:9-18.

8.Cheetham, G.M., G. Hale, H. Waldmann, and A.C. Bloomer. 1998. Crystal structures of a rat anti-CD52 (CAMPATH-1) therapeutic antibody Fab fragment and its humanized counterpart. J. Mol. Biol. 284:85-99.

9.Chen, Y., C. Wiesmann, G. Fuh, B. Li, H.W. Christinger, P. McKay, A.M. de Vos, and H.B. Lowman. 1999. Selection and analysis of an optimized anti-VEGF antibody: crystal structure of an affinity-matured Fab in complex with antigen. J. Mol. Biol. 293:865-881.

10.Jung, S., A. Honegger, and A. Pluckthun. 1999. Selection for improved protein stability by phage display. J. Mol. Biol. 294:163-180.

11.Martineau, P. and J.M. Betton. 1999. In vitro folding and thermodynamic stability of an antibody fragment selected in vivo for high expression levels in Escherichia coli cytoplasm. J. Mol. Biol. 292:921-929.

12.Tuckey, C.D. and C.J. Noren. 2002. Selection for mutants improving expression of an anti-MAP kinase monoclonal antibody by filamentous phage display. J. Immunol. Methods 270:247-257

13.O'Connell, D., B. Becerril, A. Roy-Burman, M. Daws, and J.D. Marks. 2002. Phage versus phagemid libraries for generation of human monoclonal antibodies. J. Mol. Biol. 321:49-56.

14.Goletz, S., P.A. Christensen, P. Kristensen, D. Blohm, I. Tomlinson, G. Winter, and U. Karsten. 2002. Selection of large diversities of antiidiotypic antibody fragments by phage display. J. Mol. Biol. 315:1087-1097.

15.Kovari, L.C., C. Momany, and M.G. Rossmann. 1995. The use of antibody fragments for crystallization and structure determinations. Structure 3:1291-1293.

16.Hunte, C. and H. Michel. 2002. Crystallisation of membrane proteins mediated by 
antibody fragments. Curr. Opin. Struct. Biol. 12:503-508.

17.Smith, G.P. 1985. Filamentous fusion phage: novel expression vectors that display cloned antigens on the virion surface. Science 228 : 1315-1317.

18.Williamson, R.A., R. Burioni, P.P. Sanna, L.J. Partridge, C.F. Barbas III, and D.R. Burton. 1993. Human monoclonal antibodies against a plethora of viral pathogens from single combinatorial libraries. Proc. Natl. Acad. Sci. USA 90:4141-4145.

19.Barbas, C.F., III, J.D. Bain, D.M. Hoekstra, and R.A. Lerner. 1992. Semisynthetic combinatorial antibody libraries: a chemical solution to the diversity problem. Proc. Natl. Acad. Sci. USA 89:4457-4461.

20.QuikChange ${ }^{\circledR}$ Multi Site-Directed Mutagenesis Kit. Stratagene Co., $11011 \mathrm{~N}$ Torrey Pines Rd., La Jolla, CA 92037, U.S. patent Nos. 5,789,166; 5,923,419; 6,391,548; $6,183,997 ; 5,948,663 ; 5,866,395 ; 5,545,552$; and patents pending.

21.Hogrefe, H.H., J. Cline, G.L. Youngblood, and R.M. Allen. 2002. Creating randomized amino acid libraries with the QuikChange ${ }^{\circledR}$ Multi Site-Directed Mutagenesis Kit. BioTechniques 33:1158-1165.

22.Momany, C., L.C. Kovari, A.J. Prongay, W. Keller, R.K. Gitti, B.M. Lee, A.E. Gorbalenya, L. Tong, et al. 1996. Crystal structure of dimeric HIV-1 capsid protein. Nat. Struct. Biol. 3:763-770.

23.Barbas, C.F., III, D.R. Burton, J. K. Scott, and G.J. Silverman (Eds.). 2001. Phage Display: A Laboratory Manual. CSH Laboratory Press, Cold Spring Harbor, NY.

24.Engvall, E., K. Jonsson, and P. Perlmann. 1971. Enzyme-linked immunosorbent assay. II. Quantitative assay of protein antigen, immunoglobulin G, by means of enzymelabelled antigen and antibody-coated tubes. Biochim. Biophys. Acta 251:427-434.

Received 21 May 2003; accepted 27 June 2003.

Address correspondence to Cory Momany, Room 372 Wilson Pharmacy Building, College of Pharmacy, University of Georgia, Athens, GA 30602, USA. e-mail: cmomany@mail.rx.uga.edu

\title{
Random priming PCR strategy to amplify and clone trace amounts of DNA
}

\author{
Nianxiang Zou, Susan Ditty, Bingjie Li, and Shyh-Ching Lo \\ Armed Forces Institute of Pathology, Washington, DC, USA
}

BioTechniques 35:758-765 (October 2003)

Here we report a new methodology to study trace amounts of DNA of unknown sequence using a two-step PCR strategy to amplify and clone target DNA. The first PCR is carried out with a partial random primer comprised of a specific 21-nucleotide $5^{\prime}$ sequence, a random heptamer, and a 3' TGGC clamp. The second PCR is carried out with a single 19-nucleotide primer that matches the specific 5' sequence of the partial random primer. Using human and Mycoplasma genitalium DNA as examples, we demonstrated the efficiency of this approach by effectively cloning target DNA fragments from $1 \mathrm{pg}$ DNA sample. The cloning sensitivity could reach $100 \mathrm{fg}$ target DNA templates. Compared to the strategy of first adding adapter sequences to facilitate the PCR amplification of unknown sequences, this approach has the advantage of allowing for the amplification of DNA samples in both natural and denatured forms, which provides greater flexibility in sample preparation. This is an efficient strategy to retrieve sequences from trace DNA samples from various sources.

\section{INTRODUCTION}

DNA cloning is one of the most commonly used methods in molecular biology. The technique allows one to obtain a large quantity of specific DNA molecules for study or characterization. However, there is a limitation to this powerful technique. In conventional DNA cloning, a significant amount of target molecules is needed to ensure efficient ligation with vectors. With PCR, cloning trace amounts of DNA can be achieved by first amplifying the target DNA, given that partial sequences are known for the DNA segment of interest and that PCR primers can be designed. However, cloning trace amounts of DNA with unknown sequence presents a difficult task in many situations. Conventional or regular PCRbased cloning strategies are typically unable to fulfill this task.

Many amplification strategies using small amounts of DNA or RNA with unknown sequence have been reported (15 ). Random primers tagged by a specific sequence at the $5^{\prime}$ end were commonly used to introduce primer sequences to facilitate PCR amplification (4,5). Most of these applications still require samples in nanogram amounts $(4,5)$. To attain higher sensitivity, sequence-independent single-primer amplification (SISPA) was developed to amplify unknown target DNA molecules with PCR and has been shown to facilitate cloning from $1 \mathrm{pg}$ DNA after amplification (3). SISPA first requires ligation of an adapter onto the target population of blunt-ended DNA molecules. The resulting DNA with common end sequence allows for PCR amplification by a single primer made from the adapter sequence.

Random priming strategies generating single-stranded DNA (ssDNA) molecules are frequently used to randomly multiply DNA or synthesize cDNA from RNA molecules (6). The most common applications include probe labeling, multiplying DNA or RNA from small samples, and generating random in vitro mutagenesis and recombination $(1,2,7-10)$. To clone trace amounts of unknown DNA from various sources of different physical and biological properties, we have developed a two-step PCR method that is partially based on random priming strategy. The first PCR uses a single primer composed of seven random nucleotides flanked by a specific $5^{\prime}$ tag and a $3^{\prime}$ clamp (Figure 1, Ran5-29). A PstI site (New England Biolabs, Beverly, MA, USA) is included in the $5^{\prime}$ tag. The internal seven random nucleotides and the $3^{\prime}$ clamp TGGC enable the primer to anneal with any seven nucleotides with GCCA immediately upstream. The TGGC clamp increases the primer's 3 '-specific annealing from 7 to 11 nucleotides. The second PCR is performed using a single specific 